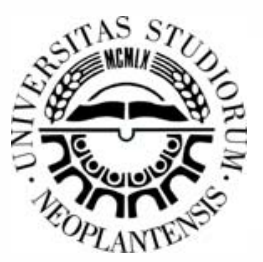

\title{
Finite Element Modelling of Clinched Joints
}

\author{
Szabolcs Jónás, ${ }^{*}$ Miklós Tisza
}

University of Miskolc, Faculty of Mechanical Engineering and Informatics, Miskolc, Hungary

\begin{abstract}
In this article the clinched joints of DP600 type steel sheets were examined by finite element method. This type of steel is a dual phase (ferritic-martensitic,) advanced high strength steel which is used mainly by the automotive industry. FE analysis was performed for further analysis and for the deeper understanding of the behaviour of the joint. The effects of the planar anisotropy, spring back and different hardening laws were examined by a 2D axisymmetric FE model in ANSYS.
\end{abstract}

Key words: clinching; DP600; FEA; simulation

\section{INTRODUCTION}

These joints are used mostly in automotive, computer and aircraft industries, but for instance according to the standards they are not allowed to be used in food industry [1], [2], [3]. The hardest goal is to use the lowest number of tests and use the articles and other available material and test data to determine the questioned parameters. The clinch joints are quite new types of joints, the first patent was accepted in 1989. This joint can be done between 2-3 thin sheet plates. The cross section of a joint can be seen in Figure 1, which shows the main geometrical parameters of a joint ( 2 sheets were joined). The undercut size ( $\mathrm{C}$ value) and the neck thickness (tN value) are highly affecting the strength of the joints. In optimal case both of them are as high as it possible. The material of the plates can be ferrous or non-ferrous at the same time, so this joint can realize dissimilar joints without any added material (weld material or glue). The joint is made by metal plastic forming by a special tool. After creating the patent the increasing industrial needs of these types of joints led the researchers to analyse the joints much more deeply. Several studies have been carried out concerning the geometry optimization of the clinching tool to achieve better joints by different optimization methods. Other studies were carried out on the so-called hybrid joints. These joints have an adhesive layer between the sheets. These joints have higher strength but they need much more time because the drying of the adhesive layer is a time-consuming process [4], [5].

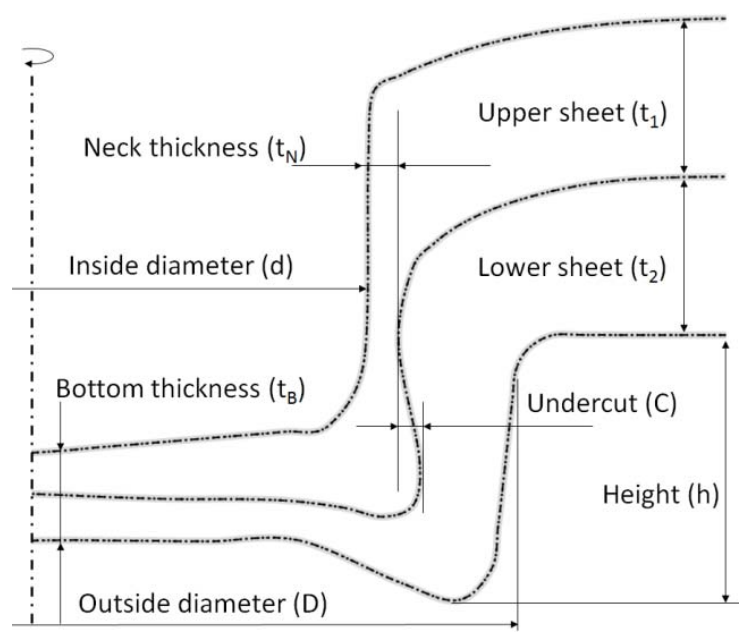

Fig. 1 Cross section of a clinched joint and its main geometrical sizes

\section{MATERIAL IDENTIRCATION}

The used material is the DP600 type of steel. The DP600 is an advanced high strength steel, which is a multiphase (ferrite and martensite) steel with excellent combination of strength and formability. The dual phase steels (DP) consist of a soft ferrite matrix with a disperse, hard second phase in the form of islands. They have high strength, high work hardening rates and high strain energy absorption properties. 100-200-600-1200 $\mu \mathrm{m}$ series of abrasive paper, $3 \mu \mathrm{m}$ polishing paste and $3 \%$ Nital was used for the specimen preparation. The measurements

*Corresponding author's.e-mail: szabolcs.jonas@gmail.com 
were done with a Carl Zeiss microscope with an image recognition software module. According to the measurements, this steel contains $\sim 23 \%$ of martensite, and its average grain size is $5 \mu \mathrm{m}$. For the chemical composition a $60 \mu \mathrm{m}$ abrasive paper was used. The measurements were performed with an Oxford Instruments Foundry Master Pro spectroscopy machine. The chemical composition can be seen in Table 1 .

Table 1 - Chemical composition (in wt\%)

\begin{tabular}{llcc}
\hline Material & $\boldsymbol{w t} \%$ & Material & $\boldsymbol{w t} \%$ \\
\hline $\mathrm{Fe}$ & 98.6 & $\mathrm{Al}$ & 0.0553 \\
$\mathrm{C}$ & 0.116 & $\mathrm{Co}$ & 0.0125 \\
$\mathrm{Si}$ & 0.171 & $\mathrm{Cu}$ & 0.074 \\
$\mathrm{Mn}$ & 0.876 & $\mathrm{Nb}$ & 0.0214 \\
$\mathrm{P}$ & $<0.005$ & $\mathrm{Ti}$ & $<0.005$ \\
$\mathrm{~S}$ & $<0.005$ & $\mathrm{~V}$ & 0.0124 \\
$\mathrm{Cr}$ & $\mathrm{W}$ & 0.0103 \\
$\mathrm{Mo}$ & 0.0262 & $\mathrm{~Pb}$ & 0.0114 \\
\hline
\end{tabular}

Tensile tests were performed with an MTS electrohydraulic testing machine to determine the mechanical properties. The results can be seen in Table 2 .

Table 2-Mechanical properties

\begin{tabular}{llcccc}
\hline Property & Dimension & Mean & $\mathbf{0}^{\circ}$ & $\mathbf{4 5}^{\circ}$ & $\mathbf{9 0}^{\circ}$ \\
\hline $\begin{array}{l}\text { UTS } \\
\text { Yield } \\
\text { strength }\end{array}$ & $\mathrm{MPa}$ & 680 & 669 & 679 & 691 \\
$\begin{array}{l}\text { Fracture } \\
\text { elongation }\end{array}$ & $\%$ & 451 & 448 & 451 & 454 \\
$\begin{array}{l}\text { Hardening } \\
\text { exponent }\end{array}$ & - & 19 & 19 & 20 & 18 \\
Anisotroy & - & 0.14 & 0.14 & 0.14 & 0.14 \\
\hline
\end{tabular}

From the tensile tests the flow curves were determined and it can be seen that the planar anisotropy has small effect on the curves. The presumption is that the planar anisotropy has no or negligible effect on the geometry of the clinch joints.

\section{FEMODEUNG}

The FE simulation model was built in ANSYS WB 18.2 [6]. The geometry of the model was built up in ANSYS Design Modeler as a parametric model. A 2D axisymmetric model is presented below (Figure 3 ). The tools were taken into consideration as linear-elastic materials, the two sheets were simulated with elasticplastic behaviour with multilinear isotropic hardening rule The tool has a spring row which was taken into consideration as an elastic body with $57 \mathrm{GPa}$ of Young's modulus. The mesh was built up by 2 nd order axisymmetrical quadrilateral and triangular elements (PLANE183). Both of the sheets contain 10 elements in thickness which provides adequate results. For better solution the edges in the contact zones were finer. The contact definition between the parts is Augmented Lagrange formulation with a frictional coefficient $\mu=0.12$ between the parts. Between the punching tool and the simplified spring row the contact definition was bonded with MPC algorithm. The duration of the simulation is 3 time steps. The simulation is performed as a displacement controlled model. According to the final, measured bottom thickness and the measured piston displacement, the vertical movement of the clinching tool was $3.25 \mathrm{~mm}$. The holder was constrained in vertical direction by a compression only support and in the 1st step a force $(\mathrm{F}=1000 \mathrm{~N})$ was applied which is constant in the 2 nd and 3rd steps. In the 3rd step the tool was removed from the joint.

The distribution of the equivalent plastic strain was checked with the unaveraged display option, because if it is not continuous, then the results are unacceptable in the point of view of nonlinear calculations. The unaveraged distribution of the plastic strain can be seen in Figure 3. The high (greater than 2) plastic strains are acceptable, according to the literature [9].

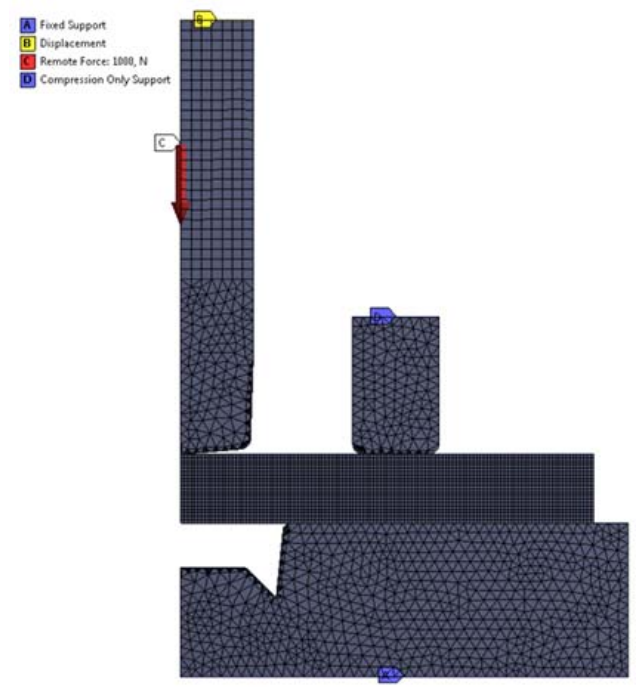

Fig. 2 FE mesh and boundary conditions of the model

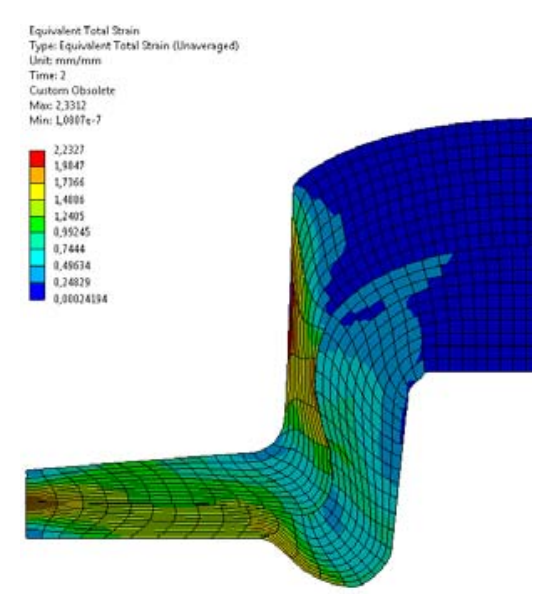

Fig. 3 Equivalent plastic strain distribution of the joint 


\section{MODE VALDATION}

In this study the formed geometry and the F-d curves were used to validate the FE results. The geometry comparison can be seen in Figure 4. The forming force displacement results of the FE model can be compared after the correction of the measured values. The difference between the model and the measurement is acceptable. The simulated curve shows a very good agreement with the measured one.

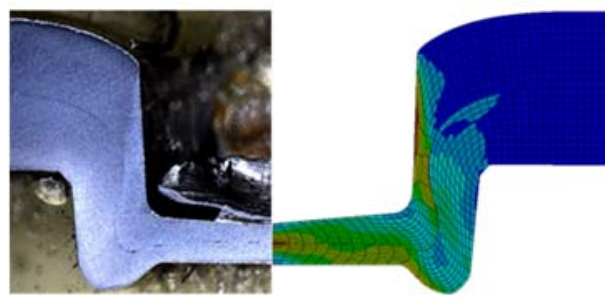

Fig. 4 Comparison of the cross sections

According to [7] the measured curve can be divided into 3 main phases and 5 steps. In Phase I. the testing machine starts to work, the punching tool moves down, the holder moves downward to fix the sheets, the tool comes into contact with the upper sheet (punch side) and the joining process is started (Step I.). The tool punches the sheets and they move together (Step I. - Step II.) and this part of the process continues until the first bending point (Step II.). The lower sheet (die side) reaches the die; that is why the slope of the curve changes after Phase I. In Phase II. the sheets start to flow around the punching tool and start to flow inside the free space of the die (Step III.). The last part of the process needs more deformation force; the curve raises with the highest slope. In Step IV. the punching tool reaches the end position. In this phase the setting force reaches the maximum also. After this point the tool starts to remove from the joint with a certain slope depeding on the stiffness of the machine. After Step $\mathrm{V}$. the joint is totally released.

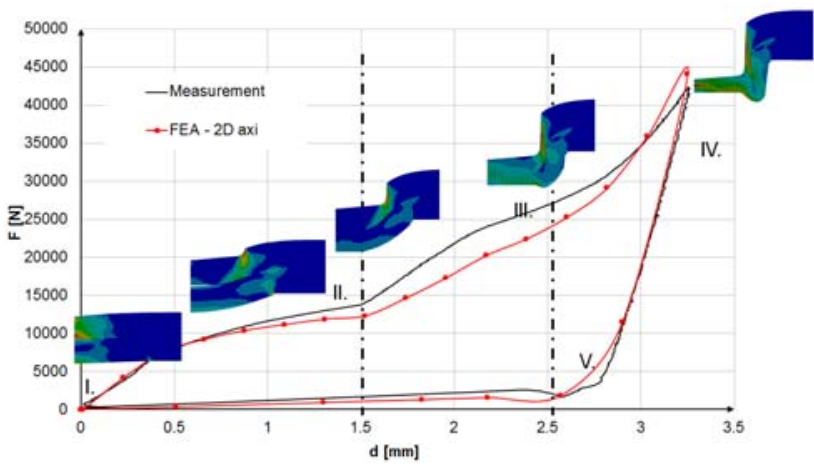

Fig. 5 Measured and calculated force-displacement curve

\section{INPLUENCE OF PLANAR ANISOTROPY AND SPRING BACKEFECT}

For rolled sheets the well-known consideration is the planar anisotropy, which means the orientation of the test specimen with respect to the direction of rolling has an effect on the mechanical properties. As it can be seen from the results (Figure 6) this effect is negligible.

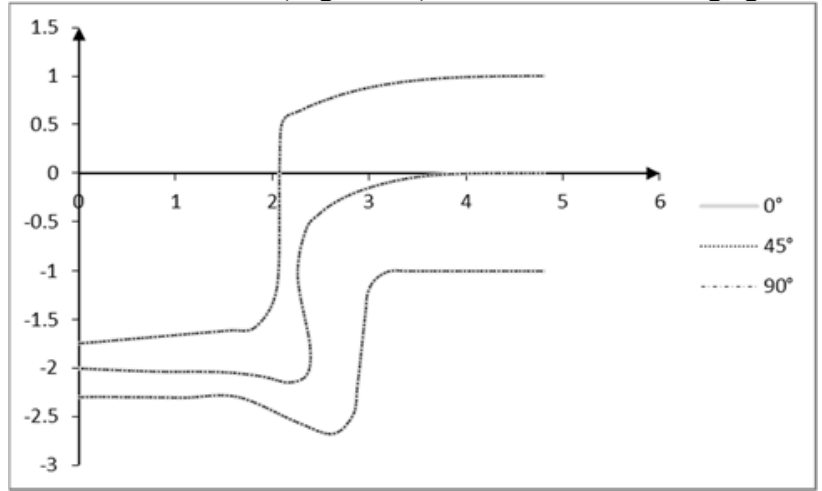

Fig. 6 Effect of planar anisotropy

The elastic recovery after the unloading is the spring back effect which is also a well-known phenomenon in sheet metal forming processes. In practice there are several techniques (e.g.: over forming) to minimize the final deviation from the goal geometry. From the simulation results of the $45^{\circ}$ oriented flow curve it can be seen that the spring back effect is also negligible in this joining process (Figure 7 and Figure 8).

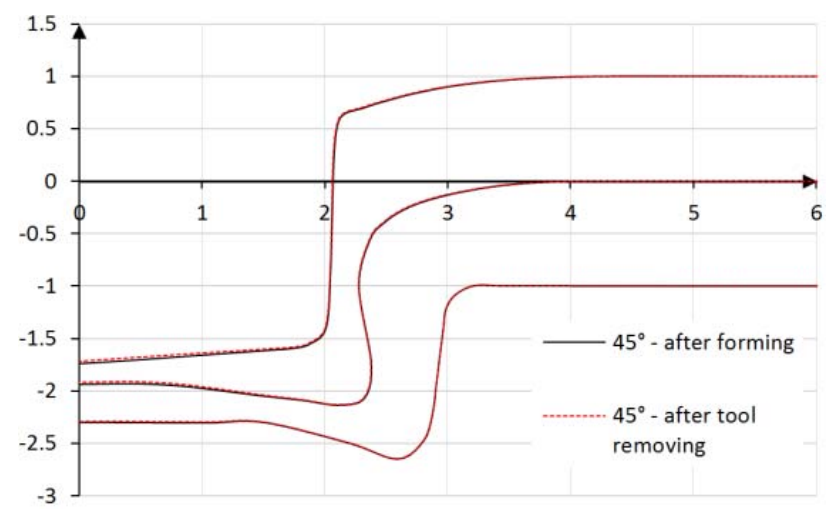

Fig. 7 Effect of spring back

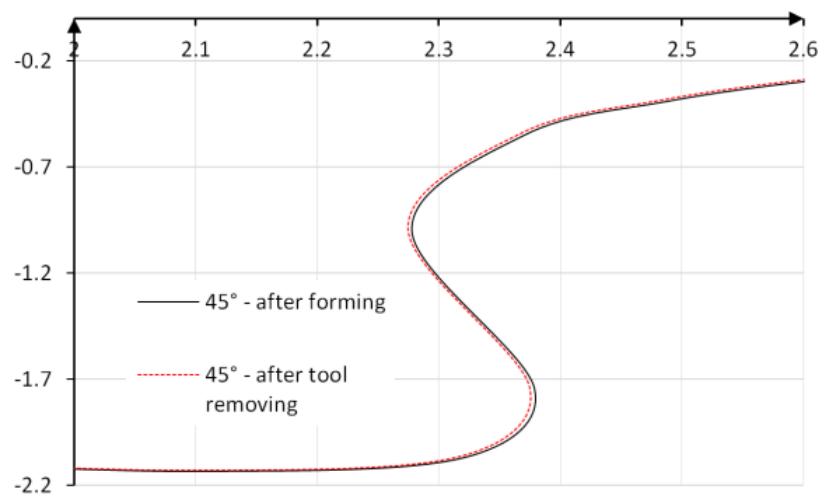

Fig. 8 Effect of spring back (undercut)

These questions were studied in the literature [9] with other types of steels, and the author observed the same phenomenon. It can be stated in the case of clinch joints that the planar anisotropy and the spring back effect are negligible. 


\section{INFLUENCE OFROWOURVE}

Severe plastic deformation occurs during the forming process (Step III. according to Figure 5). As already stated, true plastic strains of the order of 2-3 are not unusual and stress-strain data far beyond the maximum uniform strain have to be available for the analysis [9]. For better simulation results the use of extrapolation methods are necessary. In this section the influence of the different hardening laws is presented through the comparison of the undercuts. In this study four hardening laws were presented. The parameter identification was done by the least-squares method. The used hardening laws follow the Eq. (1-4):

$k_{f}^{N a ́ d a i}=K \cdot \varphi^{n}$

$k_{f}^{\text {swift }}=K \cdot(m+\varphi)^{n}$

$k_{f}^{\text {Voce }}=K \cdot\left(1-m \cdot e^{-n \varphi}\right)$

$k_{f}^{\text {Swift-Voce }}=\alpha \cdot k_{f}^{\text {Swift }}+(1-\alpha) \cdot k_{f}^{\text {Voce }}$

Constants of the equations can be seen in the following table (Table 3):

Table 2-Extrapolation model parameters

\begin{tabular}{lccc}
\hline & $\boldsymbol{K}[\mathbf{M P a}]$ & $\boldsymbol{m}[-]$ & $\boldsymbol{n}[-]$ \\
\hline Nádai & 1013.1 & - & 0.1329 \\
Swift & 1063.9 & 0.0023 & 0.1533 \\
Voce & 772.13 & 26.17 & 0.4149 \\
\hline
\end{tabular}

In case of the mixed or combined model (Swift-Voce) the $\alpha=0.7495$, which is a weighting factor of the two laws. Figure 9 shows the curves fitted to the measured one.

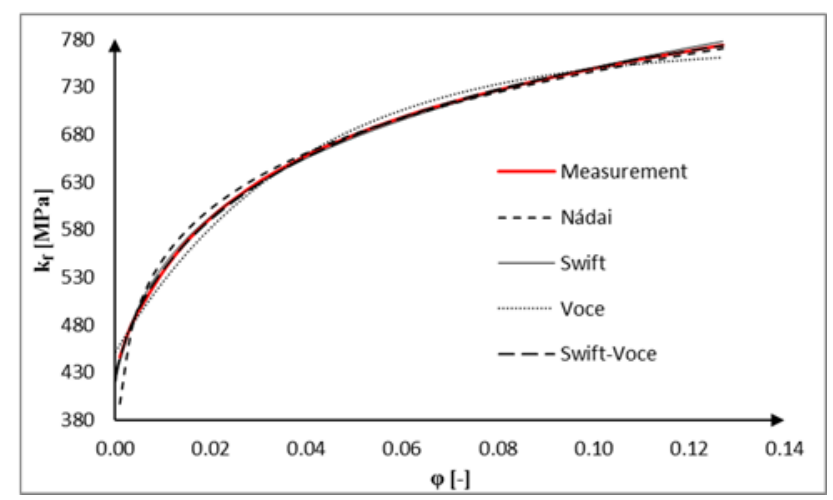

Fig. 9 Extrapolation methods - parameter identification

Figure 11 shows the undercuts with the different methods. The Nádai and the mixed equations resulted nearly the same sized undercut as it can be presumed according to the extrapolated curves (Figure 10). The difference is quite large $(\sim 14 \%)$ between the Voce and the Swift strainhardening models in the undercut region.

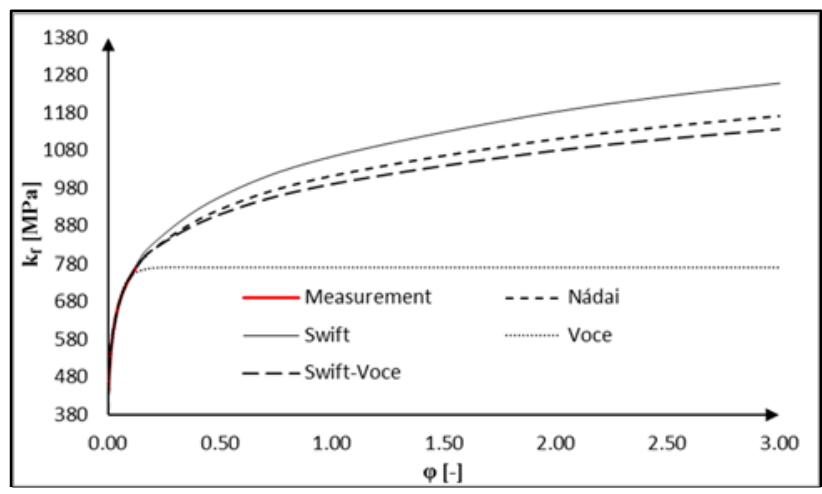

Fig. 10 Extrapolated flow curves

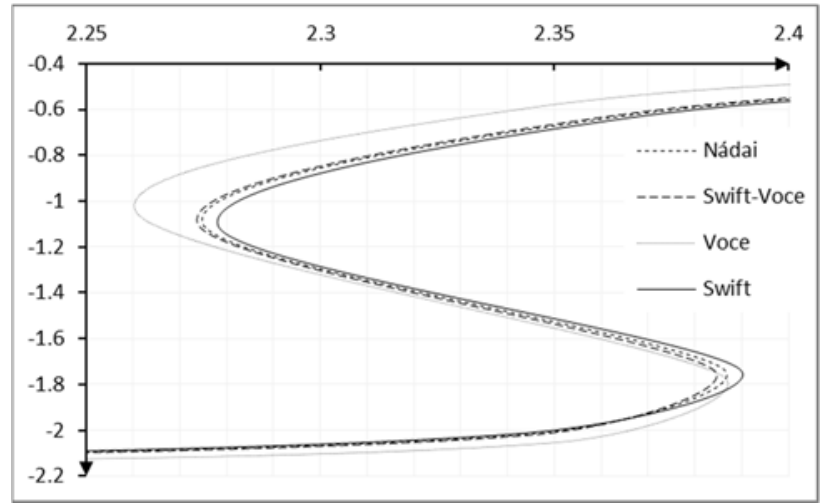

Fig. $\mathbf{1 1}$ Influence of the hardening laws to the undercut

\section{CONCLUSION}

In this article the FE modeling of the clinch joints was performed. With the validated model some influencers were analyzed. According to the literature and the simulations it can be stated that the planar anisotropy and the spring back effect are negligible. The used extrapolation method is an interesting question in forming simulation. As it can be seen the different methods give different results.

\section{REFERENCES}

[1] M. Tisza, G. Gaszton, A. Kiss, P. Z. Kovács, Zs. Lukács Alakítható nagyszilárdságú lemezanyagok klincs kötése, Multidiszciplináris tudományok, 4. kötet. (2014), I. sz. pp. 49-58.

[2] Kovács P. Z., Tisza M. Klincs kötés technológiai paramétereinek vizsgálata, végeselemes modellezésel, Anyagmérnöki Tudományok, 39/1 (2016) pp. 7-18.

[3] Béres G., Danyi J., Végvári F., Clinching of steel sheets used in automotive industry, In: Nicolae Balc (ed.) Modern Technologies in Manufacturing, vol. 808 pp. (2015) 75-79.

[4] T. Sadowski, T. Balawender, P. Golewski, Technological aspects of manufacturing and numerical modelling of clinch-adhesive joints, Springer, 2015 
[5] L. Kascák, E. Spisák, Clinching as a non-standard method for joining materials of dissimilar properties, Zeszyty naukowe politechniki rzeszowskiej Nr. 284. Mechanika z. 84, (2012), pp. 31-41.

[6] ANSYS WB 18.2 User's guide

[7] Y. Tan, O. Han, F. Du, Process Monitoring Method with Window Technique for Clinch Jointing, ISIJ International, Vol. 45 No. 5. pp. (2005), pp.723-729
[8] S. Coppieters, S. Cooreman, H. Sol, D. Debruyne, Reproducing the experimental strength of clinched connections with finite element methods, International Journal of Material Forming, 2011, Volume 4, Number 4, pp. 429

[9] S. Coppieters, Experimental and numerical study of clinched connections, $\mathrm{PhD}$ dissertation, $\mathrm{KU}$ Leuven, 2012. 